\title{
Cardiac Hypertrophy in Rats with Iron and Copper Deficiency: Quantitative Contribution of Mitochondrial Enlargement
}

\author{
Joseph R. Goodman ${ }^{[31]}$, Joseph B.Warshaw and Peter R.Dallman \\ Department of Pediatrics and the Veterans Administration Hospital, University of California, \\ San Francisco Medical Center, San Francisco, California, and the Children's Service, Massachusetts \\ General Hospital and Department of Pediatrics, Harvard Medical School, Boston, Massachusetts, USA
}

\begin{abstract}
Extract
Quantitative studies of the ultrastructure of heart muscle in iron- and copper-depleted rats show an increased mitochondrial area that contributes to cardiac hypertrophy in both conditions. The mean ratios of mitochondrial/myofibrillar areas are 1.73 and 1.69, respectively, in the deficient groups compared with 0.70 in control animals. The markedly enlarged mitochondria appear to displace and distort the myofibrils. After iron-deficient rats are provided with iron, the reversal of the abnormal mitochondrial/myofibrillar ratio and of cardiac hypertrophy requires about 16 days or approximately twice as long as the complete repair of anemia.

In heart muscle from iron-deficient animals, the mitochondrial cytochromes, which all contain iron, remain essentially normal in concentration. In the copper-deficient rats, in contrast, cytochrome $a+a_{3}$, which contains copper, is depressed to less than one-half the normal concentration. Isolated mitochondria from heart and liver of all animals deficient in iron and copper function normally with respect to respiration and phosphorylation. Thus, a correlation between abnormality of mitochondrial structure, composition, and function is not as yet apparent.

The mitochondrial contribution to the cardiac hypertrophy of iron and copper deficiency cannot be attributed entirely to increased work load secondary to anemia, particularly in copper-deficient rats whose cardiac enlargement precedes the development of anemia. The morphologic changes are distinct from those observed in experimental work hypertrophy and can represent a response to the lack of essential precursors required for the cytochromes or other mitochondrial constituents.
\end{abstract}

\section{Speculation}

Cardiac hypertrophy in iron and copper deficiency is in part attributable to enlargement of the mitochondrial compartment. This results from the lack of trace metals required for the production of cytochromes or other mitochondrial constituents.

\section{Introduction}

Dietary deficiency of iron and copper produce in the rat a striking enlargement of the mitochondria in heart muscle, liver, and exythroid precursors of bone marrow [8]. The ultrastructure of the mitochondria appears less electron dense and is characterized by somewhat less closely packed cristae. In mice, similar mor- 
phological changes are seen in hepatocytes after treatment with the copper-chelating agent cuprizone [23], and in response to a riboflavin-deficient diet [24]. Each of these deficiency states results in depletion of components of the electron-transport chain which are localized in the mitochondrial cristae $[2,7,10]$. This depletion appears to be the common feature in the production of the altered mitochondrial structure. Iron in the form of heme occurs in each of the cytochromes; in addition, there are large amounts of nonheme iron in succinate dehydrogenase, NADH dehydrogenase, and complexes I, II, and III of the electrontransport chain [3]. Copper is a component of cytochrome oxidase, the terminal acceptor of the electrontransport chain [18]. Riboflavin is required for production of flavin enzymes involved in mitochondrial electron transport [2].

This study was designed to achieve the following objectives: to obtain a quantitative estimate of the degree of enlargement of the mitochondrial compartment in the myocardium of iron- and copper-deficient animals; to assess the functional status of the cardiac mitochondria with respect to oxidation and phosphorylation; and to determine the reversibility of the morphological abnormality upon institution of a complete diet.

Methods

Male rats of the Wistar strain were fed iron- [10] or copper-deficient diets [7] starting at 10 days of age (groups IIB and III, table I); iron-deficient group II A was started on the diet at 36 days of age to provide a briefer period of depletion. All animals received the same diet based upon partially skimmed milk with a vitamin and mineral supplement containing no added iron or copper salts. Weighed quantities of diet were given daily to rats in group IB to restrict their growth to approximate that of iron-deficient group IIB. This method of restricting intake was chosen over an isocaloric control because of the difficulty of accurately measuring the intake of a powdered diet. Other groups had free access to the diet. Groups I A and IB, which received the complete diet were also given copper (40 mg cupric sulfate/liter) and iron (250 mg ferrous ammonium citrate/liter) in their drinking water at levels previously found to be adequate $[7,10]$. In the deficient diets one or the other of the salts was omitted. Essentially identical treatment for producing iron and copper deficiency had previously been shown to deplete liver hydrolyzable iron and copper, respectively, in addition to depressing hemoglobin and cytochrome concentrations $[7,10]$. Iron-deficient rats in group II B were repleted by an initial intramuscular injection of $5 \mathrm{mg}$ elemental iron as iron dextran [29], followed by iron supplementation in the drinking water as in the complete dietary regimen.

All animals were killed between 60 and 70 days of age after an overnight fast. Tissues were removed promptly and processed for electron microscopy. The hearts were weighed after the auricular appendages and the great vessels had been cut off and the blood removed from both ventricular cavities. Heart weight correlates relatively closely with body weight in the rat [12]. Furthermore, the growth of the heart relative to total body growth is not measurably influenced under a variety of dietary conditions [13]. We thus adopted as an operational definition of cardiac hypertrophy an increase in heart weight/body weight (heart weight ratio) compared with that of control animals. Hemoglobin was determined as cyanmethemoglobin [6].

Samples of tissue for electron microscopy were taken from the left ventricle and fixed in either $1 \%$ buffered osmium or $1 \%$ buffered glutaraldehyde, postfixed in $1 \%$ buffered osmium, dehydrated in alcohol, and embedded in Maraglas. Sections were cut and stained with uranyl acetate and lead citrate. Since mitochondria are somewhat more abundant near the nuclei than elsewhere in the cytoplasm, care was taken to select fields randomly. The ratio of mitochondrial to myofibrillar area was estimated in $20-30$ prints, $20 \mathrm{~cm}$ by $25 \mathrm{~cm}$, covering an area of at least $4,500 \mu^{2}$. Areas occupied by mitochondria and myofibrils were then cut out and weighed. Collections of glycogen were excluded. The two methods of fixation yielded identical mitochondrial/myofibrillar ratios.

Mitochondria for respiratory studies were prepared by a slight modification of the method of CHANGE and Haginara [4] and oxidative phosphorylation was measured polarographically by the method of CHANGE and Williams [5]. Measurements were carried out at $25^{\circ}$ in a total volume of $1.5 \mathrm{ml}$ containing $0.2 \mathrm{M}$ sucrose,

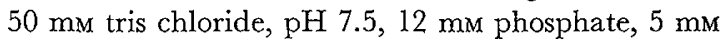
$\mathrm{MgCl}_{2}, 1 \mathrm{~mm}$ EDTA, $10 \mathrm{~mm} \mathrm{NaCl}$, and $5 \mathrm{~mm}$ substrate (glutamate-malate or succinate). The $\mathrm{ADP} / \mathrm{O}$ ratios were determined after the addition of substrate and limiting amounts of ADP as described by CHANCE and Williams [5]. This ratio is calculated from the number of moles of adenosine diphosphate (ADP) phosphorylated to the number of gram atoms of oxygen consumed, and expresses the yield of oxidative phosphorylation. Difference spectra were performed as previously described [7], with mitochondrial fractions isolated from heart muscle by the method of TYLER and Gonze [25]. Two or three hearts were pooled for each determination and two to three spectra were obtained for each group of animals. 


\section{Results}

Cardiac hypertrophy (defined as an increase in heart weight/body weight (or heart weight ratio) compared with each of the control groups) was present in all groups of iron- and copper-deficient animals $(P<0.01$, $t$ test). Cardiac weight, as percentage of body weight, was similar in rats fed ad libitum (IA) and in those whose intake was restricted to match the growth of the severely iron-restricted group (IB) (table I). Growth retardation, anemia, and cardiac enlargement relative to the weight of the animal were more striking in rats on the low iron diet for 7 weeks (group IIB) than for 3 weeks (group IIA). The copper-deficient animals (group III) developed marked cardiac enlargement, though growth retardation and anemia were minimal. The animals listed in table I are those employed for studies of ultrastructure. Rats used in the biochemical assays had essentially the same characteristics.

\section{Electron Microscopy}

Figures 1 and 2 show the ultrastructural appearance of the myocardium of representative animals from the complete diet, weight-restricted (IB) and the irondeficient (IIB) groups, respectively. These sections are compared because the degree of retardation of growth was similar in the two groups. Sections from the group fed the complete diet, ad libitum (IA) and the copper-deficient (III) group are shown in figures 3 and 4, respectively. These groups also had similar body weights. In the animals fed the complete diet, the area occupied by myofibrils exceeded that of the mitochondria, in contrast to the deficient groups, where mito- chondria occupied the larger area. This is expressed quantitatively in table II. After 3 weeks of an irondeficient regimen (IIA), there was a significant increase in the mitochondrial/myofibrillar ratio compared with control groups I A and IB $(P<0.01)$, even though anemia was not severe. After 7 weeks of the regimen (group IIB), there was a further increment in the ratio. The magnitude of ultrastructural changes in copper-depleted animals was similar to group IIB.

Individual mitochondria in deficient animals (groups IIA, IIB) appeared larger than normal; it was not clear whether there was an increase in their number (fig. 1-4). Cardiac mitochondria normally have an irregularly indented ovoid shape, so that tangential sections could traverse several different portions of the same organelle. This renders the quantitation of size and number of cardiac mitochondria more difficult than with the more uniform and evenly ovoidshaped liver mitochondria. The mitochondria in the iron-deficient animals (fig.2) appeared less compact and more irregular in shape than in control animals (fig. 1). Parts of some mitochondria appeared to be indented and limited by a single membrane rather than the usual double membrane; this was most commonly evident in adjoining portions of two mitochondria (fig. 5).

\section{Rate of Reversal after Institution of a Complete Diet}

The anemia in iron-depleted animals (IIB) treated with iron was repaired within 8-9 days, as in similar groups of animals reported previously [10]. The return to normal heart weight ratio is shown in table III. After 9 days of feeding a complete diet some increase in heart weight ratio remained; by 16 days, excess in

Table I. Cardiac hypertrophy in iron-deficient and copper-deficient rats

\begin{tabular}{|c|c|c|c|c|c|}
\hline \multirow[t]{2}{*}{ Group } & \multirow[t]{2}{*}{ Type of $\operatorname{diet}^{1}$} & \multicolumn{2}{|c|}{$\mathrm{Wt}, \mathrm{g}$} & \multirow{2}{*}{$\begin{array}{l}\text { Heart wt/ } \\
100 \mathrm{~g} \text { body wt }\end{array}$} & \multirow{2}{*}{$\begin{array}{c}\text { Hemoglobin, } \\
\mathrm{g} / 100 \mathrm{ml}\end{array}$} \\
\hline & & Body & Heart & & \\
\hline I A & Complete diet, ad libitum (6) & $\begin{array}{c}222^{2} \\
(170-285)^{2}\end{array}$ & $\begin{array}{c}0.63 \\
(0.46-0.78)\end{array}$ & $\begin{array}{c}0.28 \\
(0.27-0.31)\end{array}$ & $\begin{array}{c}15.4 \\
(15.2-15.8)\end{array}$ \\
\hline IB & Complete diet, restricted (4) & $\begin{array}{c}95 \\
(92-97)\end{array}$ & $\begin{array}{c}0.26 \\
(0.24-0.28)\end{array}$ & $\begin{array}{c}0.28 \\
(0.26-0.29)\end{array}$ & $\begin{array}{c}17.0 \\
(16.4-18.0)\end{array}$ \\
\hline II A & Iron deficient (6) & $\begin{array}{c}166 \\
(155-182)\end{array}$ & $\begin{array}{c}0.62 \\
(0.57-0.67)\end{array}$ & $\begin{array}{c}0.37 \\
(0.35-0.46)\end{array}$ & $\begin{array}{c}8.1 \\
(6.7-10.5)\end{array}$ \\
\hline IIB & Iron deficient $(6)$ & $\begin{array}{c}104 \\
(78-128)\end{array}$ & $\begin{array}{c}0.62 \\
(0.49-0.81)\end{array}$ & $\begin{array}{c}0.65 \\
(0.51-0.93)\end{array}$ & $\begin{array}{c}3.8 \\
(3.0-4.6)\end{array}$ \\
\hline III & Copper deficient (4) & $\begin{array}{c}216 \\
(190-230)\end{array}$ & $\begin{array}{c}1.01 \\
(0.89-1.13)\end{array}$ & $\begin{array}{c}0.46 \\
(0.41-0.50)\end{array}$ & $\begin{array}{c}12.3 \\
(11.8-12.8)\end{array}$ \\
\hline
\end{tabular}

1 Number in parentheses indicates number of animals.

2 Mean and range. 


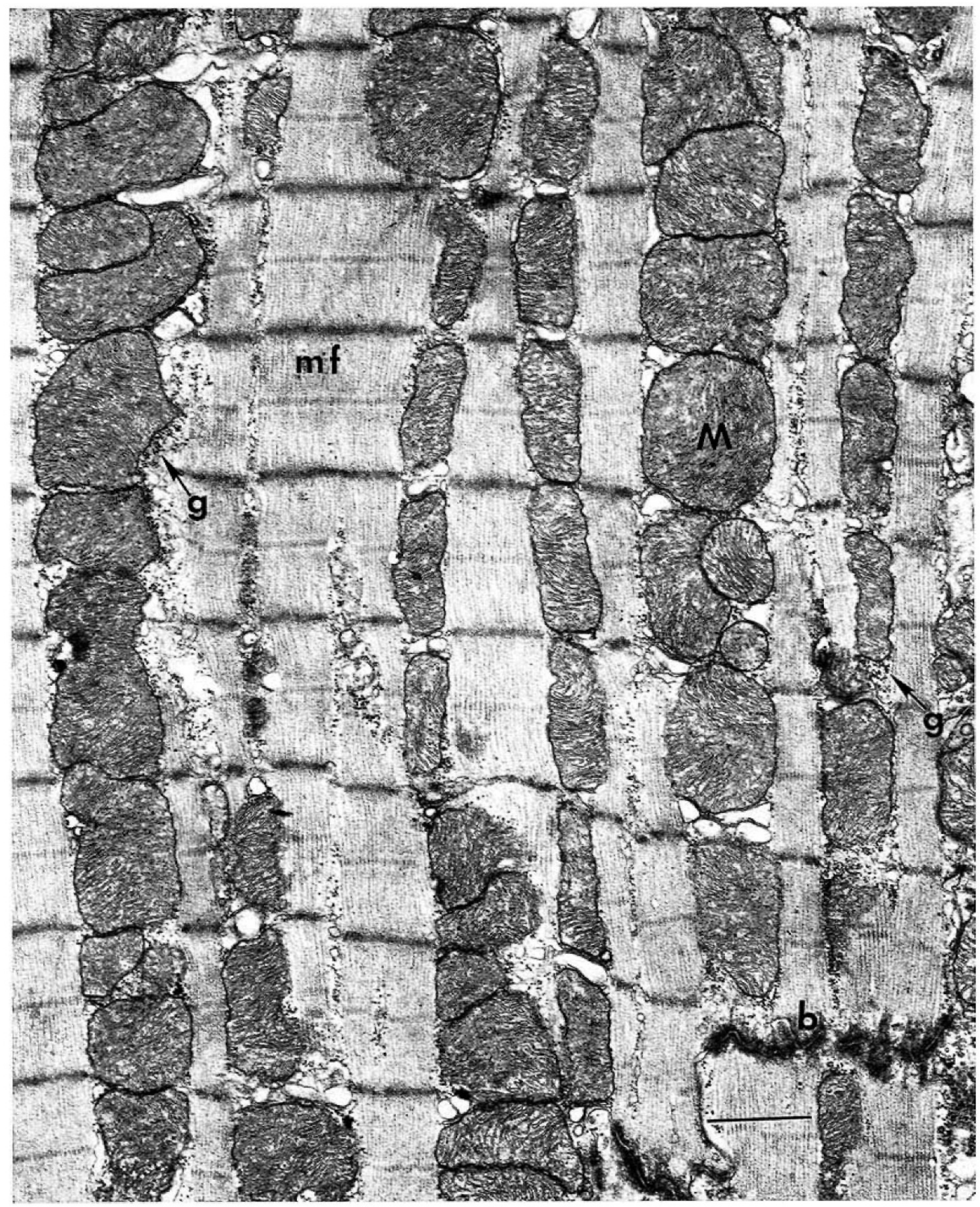

Fig. 1. Myocardium from a complete diet, weight-restricted rat (IB). There is a normal, orderly arrangement of rows of mitochondria and myofibrils. $\mathrm{M}=$ Mitochondria; $\mathrm{mf}=$ myofibrils; $\mathrm{g}=$ glycogen; and $\mathrm{b}=$ cell boundary. The scale is $1 \mu$. 


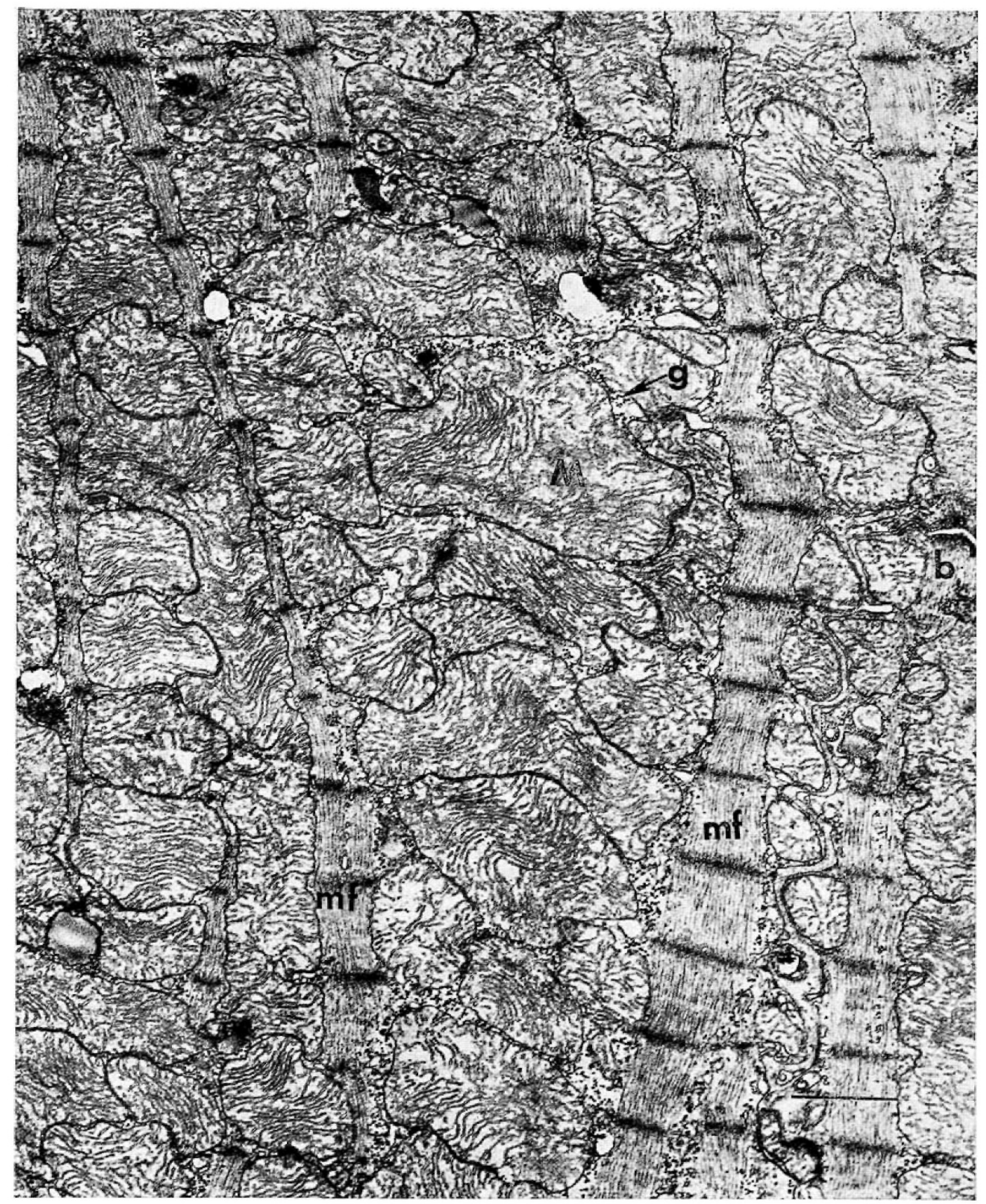

Fig. 2. Myocardium from an iron-deficient rat (IIB) at the same magnification as figure 1. There is a great increase in the area occupied by mitochondria. Myofibrils are smaller and their arrangement in relationto the mitochondria is less orderly. $\mathrm{M}=$ Mitochondria $; \mathrm{mf}=$ myofibrils $; \mathrm{g}=$ glycogen; $\mathrm{b}=$ cell boundary. The scale is $1 \mu$. 


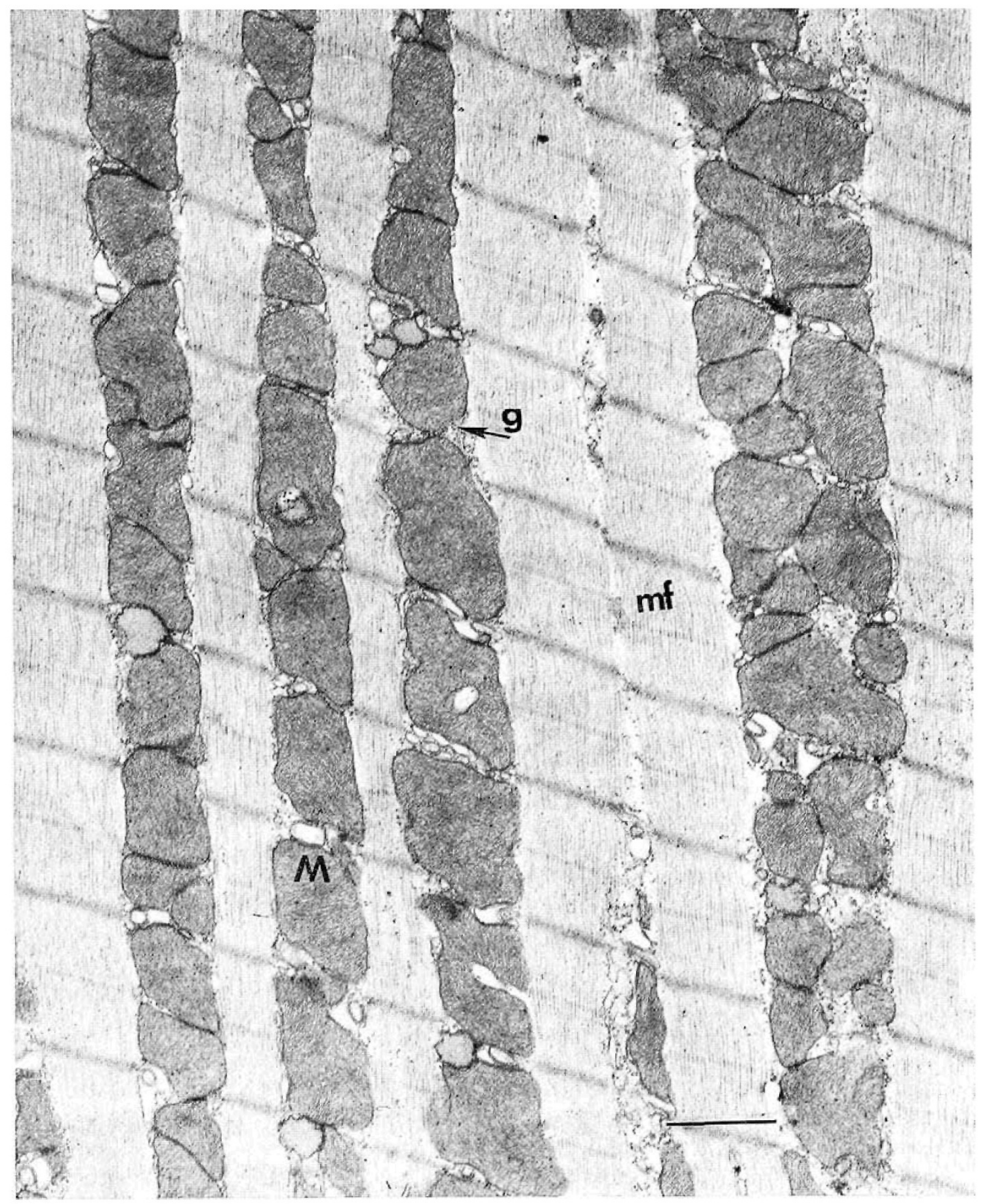

Fig.3. Myocardium from a rat fed a complete diet, ad libitum (IA). The mitochondria and myofibrils have a normal, orderly arrangement. $\mathrm{M}=$ Mitochondria; $\mathrm{mf}=$ myofibrils; $\mathrm{g}=$ glycogen. The scale is $1 \mu$. 


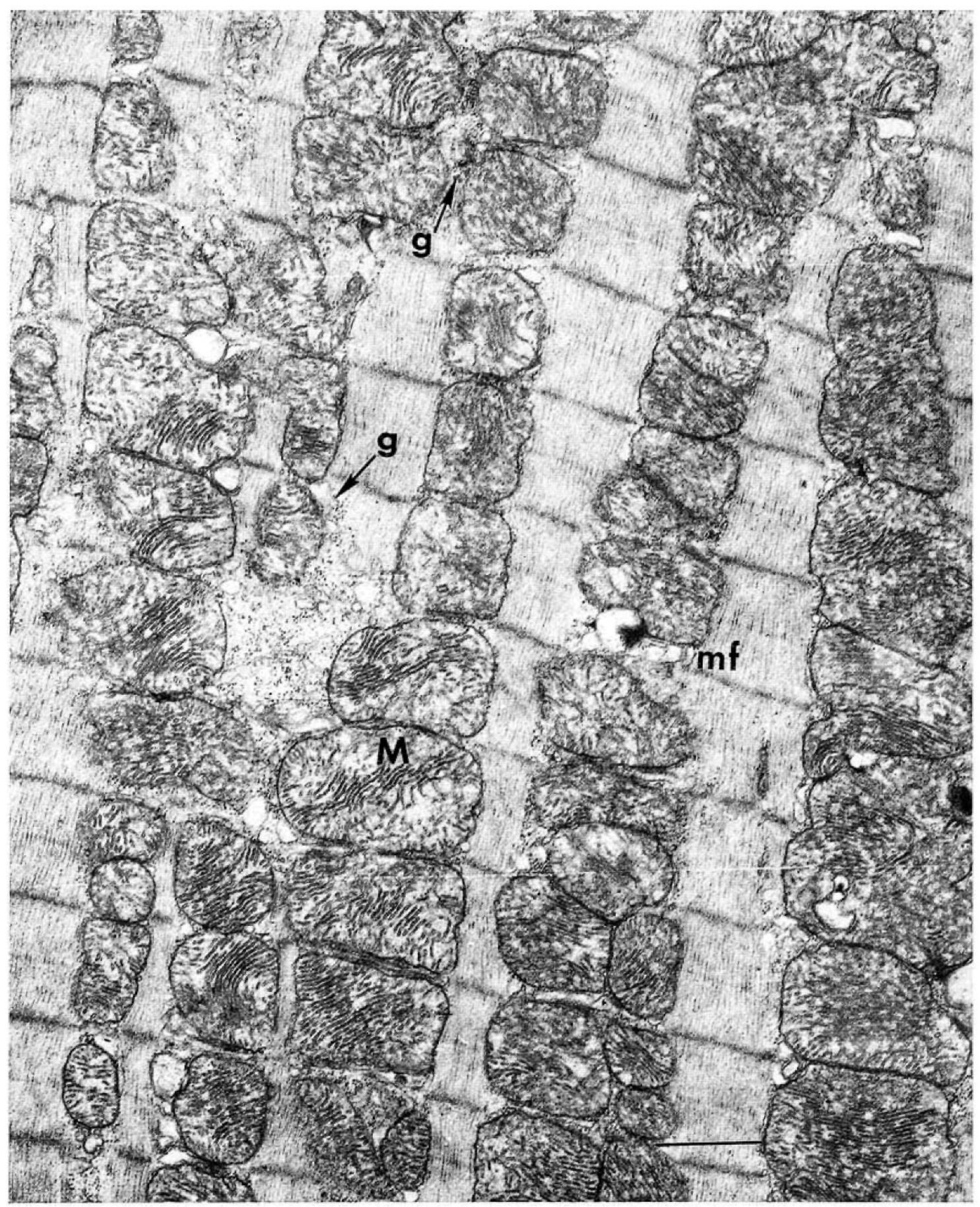

Fig.4. Myocardium from a copper-deficient rat (III) at the same magnification as figure 3. The mitochondrial area is enlarged but the arrangement of mitochondria and myofibrils is more nearly normal than in the irondeficient animal (fig.2). $\mathrm{M}=$ Mitochondria; $\mathrm{mf}=$ myofibrils; $\mathrm{g}=$ glycogen. The scale is $1 \mu$. 


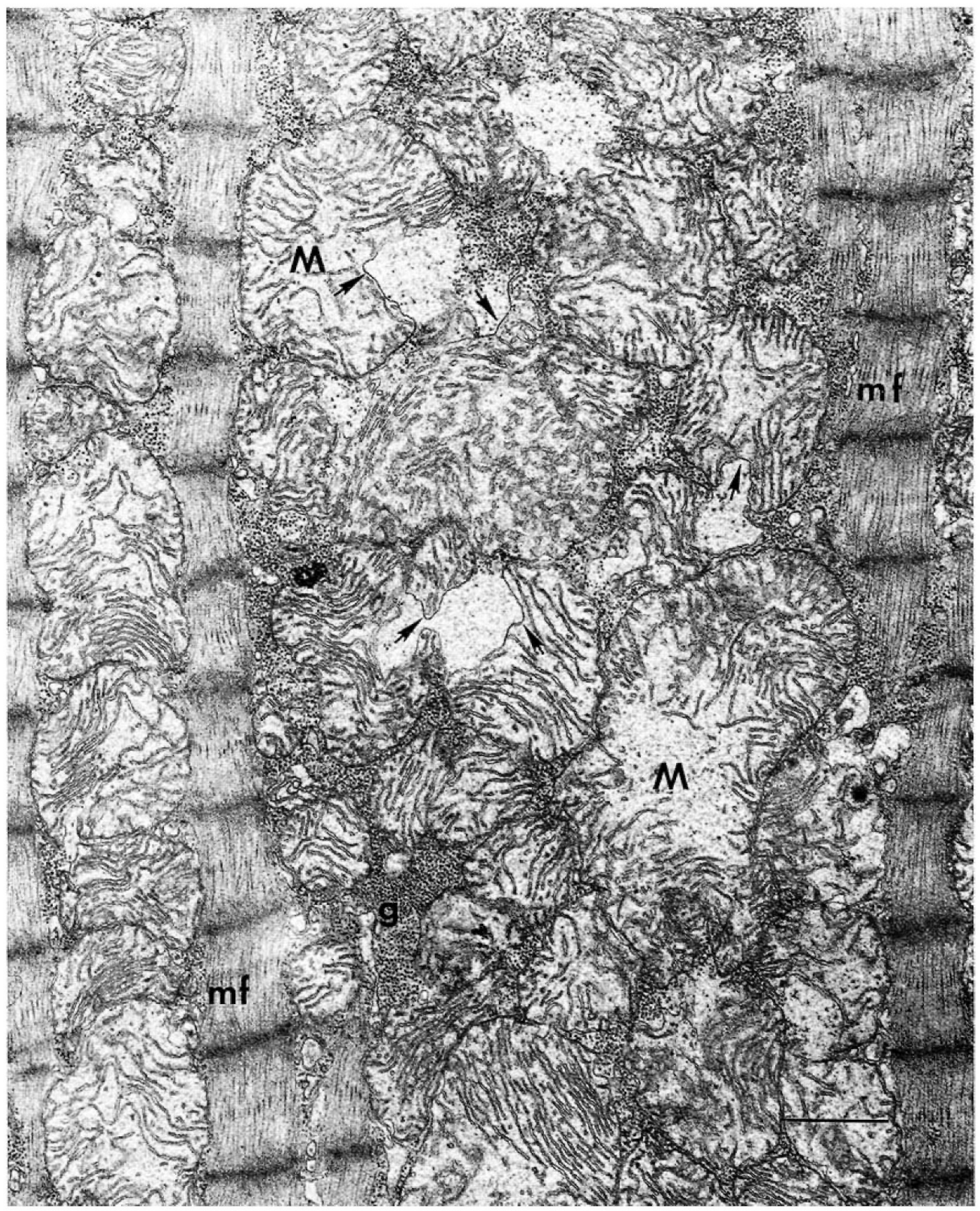

Fig. 5. Myocardium from an iron-deficient rat (group IIB). Many mitochondria include areas that have only a single limiting membrane instead of the usual double membrane; this is most commonly evident in adjoining portions of two mitochondria (arrows). $\mathrm{M}=$ Mitochondria; $\mathrm{mf}=$ myofibrils; $\mathrm{g}=$ glycogen. The scale is $1 \mu$. 
Table II. Mitochondrial and myofibrillar areas determined by planimetry

\begin{tabular}{llcc}
\hline Group & Type of diet & & \multicolumn{2}{c}{$\begin{array}{c}\text { Mitochondrial/ } \\
\text { myofibrillar area }\end{array}$} \\
\cline { 3 - 4 } & & Mean & Range \\
\hline IA & $\begin{array}{l}\text { Complete diet, } \\
\text { ad libitum (6) }\end{array}$ & 0.70 & $0.62-0.75$ \\
IB & Complete diet, & 0.71 & $0.68-0.74$ \\
& restricted (4) & 1.20 & $0.93-1.49$ \\
II A & Iron deficient (4) & 1.73 & $1.42-1.98$ \\
IIB & Iron deficient (6) & 1.69 & $1.25-2.69$ \\
III & Copper deficient (4) & & \\
\hline
\end{tabular}

${ }^{1}$ Number in parentheses indicates number of animals

Table III Regression of cardiac hypertrophy after treatment of iron deficiency

\begin{tabular}{llcc}
\hline Group & Type of diet & \multicolumn{2}{c}{$\begin{array}{c}\text { Heart wt/ } \\
100 \text { g body wt }\end{array}$} \\
\cline { 3 - 4 } & & Mean & Range \\
\hline I A & Complete diet, & & \\
& ad libitum (6) & 0.28 & $0.27-0.31$ \\
IB & Complete diet, & & \\
& restricted (4) & 0.28 & $0.26-0.29$ \\
IIB & Iron deficient (2) & 0.76 & $0.58,0.93$ \\
IIB & Iron repleted & & \\
& $\quad$ 2 days (2) & 0.61 & $0.52,0.69$ \\
& 5 days (2) & 0.46 & $0.43,0.48$ \\
& 9 days (2) & 0.47 & $0.46,0.48$ \\
& 16 days (2) & 0.36 & $0.32,0.40$ \\
\hline
\end{tabular}

${ }^{1}$ Number in parentheses indicates number of animals.

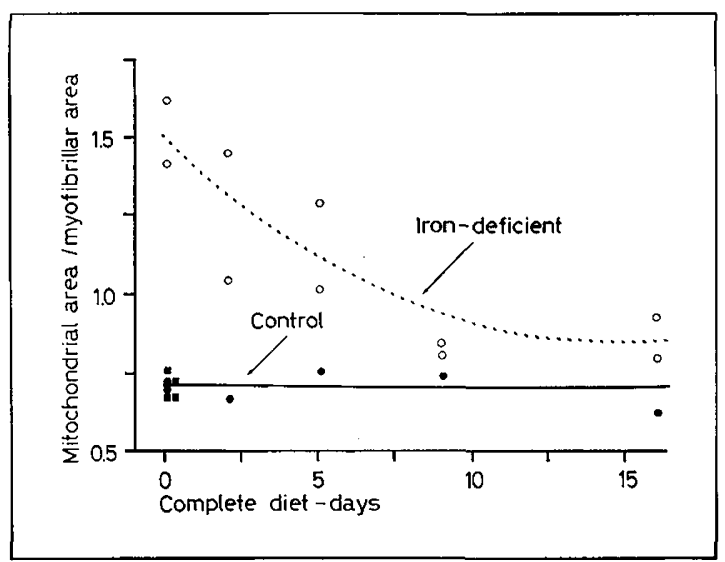

Fig.6. Mitochondrial area relative to myofibrillar area during repair of iron deficiency. Iron-deficient rats cardiac weight was slight. A similar rate of reversal of cardiac enlargement was observed in copperdeficient animals after treatment with copper [7].

The rate of change in the mitochondrial/myofibrillar ratio after treatment of the iron-depleted group IIB is shown in figure 6 . The ratio returned toward control values within 8 days and appeared close to complete by 16 days of treatment. Hypertrophy and the relative increase in mitochondrial area were reversed at similar rates.

\section{Mitochondrial Cytochrome Composition and Respiratory Function}

Figure 7 shows representative difference spectra from copper-depleted (III) and iron-depleted (IIB) animals. The height of the peaks at 550 and $605 \mathrm{~m} \mu$ reflects the relative concentrations of cytochromes $c+c_{1}$ and $a+a_{3}$, respectively. As reported previously [7], copper-deficient animals had a marked depression of cytochromes $a+a_{3}$ (cytochrome oxidase); however, the proportions of cytochromes $c+c_{1}$ to $a+a_{3}$ appeared normal in iron-deficient animals. Although no precise estimates of mitochondrial yield were obtained, the data when viewed in combination with that from previous studies indicate that 1) in iron-deficient rats the myocardial cytochrome concentrations are less depressed than in most other tissues [9] and the cytochromes are present in normal proportions; and that 2 ) in copper deficiency the cytochrome $a+a_{3}$ concentration is depressed in relation to the other cytochromes that appear to be present in normal amounts [7].

The ADP/O ratios (moles of adenosine diphosphate phosphorylated/gram atom of oxygen consumed) of mitochondria isolated from hearts and livers of control and deficient animals were similar (table IV). The $\mathrm{ADP} / \mathrm{O}$ ratios with glutamate-malate as substrate were 2.5-3.0 in both control and copper- and iron-deficient groups. Also, no differences were observed between control and deficient groups when succinate was used as the substrate. In each case, the values lie in the anticipated normal range. Oxidation rates and respiratory control ratios were also similar in the control and deficient groups. Mitochondrial yields from the depleted hearts averaged about one-half of control values. This is thought to reflect either loss of large, readily

(group IIB) were given a single intramuscular injection of $5 \mathrm{mg}$ elemental iron as iron dextran and were then fed the complete diet ad libitum. $\bullet$ : complete diet, ad libitum (IA). n: complete diet, weight restricted (IB). The return toward a normal mitochondrial/ myofibrillar ratio is rapid during the first 8 days. 
Table IV. Mitochondrial respiration

\begin{tabular}{|c|c|c|c|c|c|c|c|}
\hline \multirow[t]{3}{*}{ Group } & \multirow[t]{3}{*}{ Type of diet } & \multicolumn{3}{|c|}{ Heart mitochondria } & \multicolumn{3}{|c|}{ Liver mitochondria } \\
\hline & & \multirow{2}{*}{$\begin{array}{l}\text { Mitochondrial } \\
\text { protein, } \\
\mathrm{mg} / \mathrm{g} \text { tissue }\end{array}$} & \multicolumn{2}{|c|}{$\mathrm{ADP} / \mathrm{O}^{1}$} & \multirow{2}{*}{$\begin{array}{l}\text { Mitochondrial } \\
\text { protein, } \\
\mathrm{mg} / \mathrm{g} \text { tissue }\end{array}$} & \multicolumn{2}{|c|}{$\mathrm{ADP} / \mathrm{O}^{1}$} \\
\hline & & & $\begin{array}{c}\text { Glutamate- } \\
\text { malate }\end{array}$ & Succinate & & $\begin{array}{c}\text { Glutamate- } \\
\text { malate }\end{array}$ & Succinate \\
\hline \multirow[t]{6}{*}{ I } & Complete diet & 8.4 & 2.8 & 1.7 & 13.5 & 2.5 & 1.6 \\
\hline & & 10.0 & 2.4 & 1.7 & & 2.4 & 2.0 \\
\hline & & 7.8 & 2.7 & 1.6 & & 2.2 & 1.5 \\
\hline & & 7.1 & 2.6 & 1.7 & 11.6 & 1.9 & 1.4 \\
\hline & & 16.0 & 2.7 & 1.8 & 15.0 & 2.2 & 1.6 \\
\hline & & 10.4 & 2.7 & 1.8 & 12.7 & 2.8 & 1.6 \\
\hline \multirow[t]{2}{*}{ II A } & Iron deficient & 8.5 & 3.0 & 1.7 & 13.0 & 2.7 & 1.7 \\
\hline & & 13.0 & 2.4 & 1.7 & & 2.6 & 1.7 \\
\hline \multirow[t]{2}{*}{ II B } & Iron deficient & 2.2 & 2.7 & 1.4 & & 2.5 & 1.5 \\
\hline & & 2.7 & 2.6 & 1.7 & 13.8 & 1.9 & 1.5 \\
\hline \multirow[t]{2}{*}{ III } & Copper deficient & 7.5 & 2.5 & 1.9 & 11.5 & 2.5 & 1.7 \\
\hline & & 4.4 & 2.5 & 1.7 & 9.5 & 2.4 & 1.5 \\
\hline
\end{tabular}

${ }^{1}$ Moles of adenosine diphosphate phosphorylated/gram atoms of oxygen consumed for each substrate.

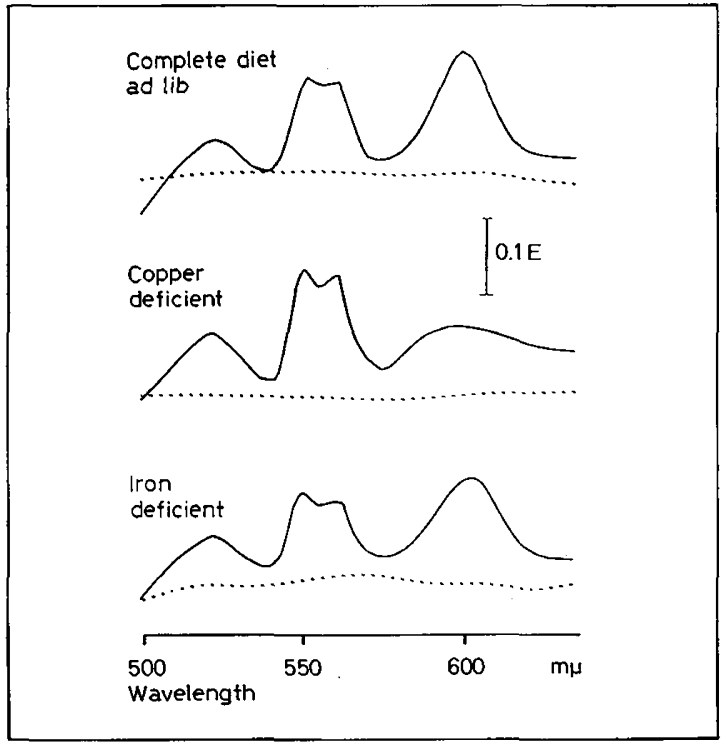

Fig.7. Difference spectra of heart mitochondria. Each cuvette contains mitochondria isolated from $0.5 \mathrm{~g}$ heart muscle, $50 \mathrm{~mm}$ phosphate buffer, $\mathrm{pH} 7.5$, and $2 \%$ sodium deoxycholate in a total volume of $1.8 \mathrm{ml}$. After obtaining a base-line tracing (dashed line), the contents of one cuvette were reduced with a few milligrams of $\mathrm{Na}_{2} \mathrm{~S}_{2} \mathrm{O}_{4}$ and the spectrum of the reduced versus the oxidized sample was determined (solid line). In the specimen from the copper-deficient animal, the height of the cytochrome $a+a_{3}$ peak ( $605 \mathrm{~m} \mu$ ) relative to the $c+c_{1}$ peak $(550 \mathrm{~m} \mu)$ is less than one-half compared with the specimen from the animal fed the com- sedimented mitochondria in the nuclear pellet or loss into the mitochondrial supernatant fraction due to increased fragility.

\section{Discussion}

In man, the cardiac hypertrophy that accompanies severe iron deficiency is generally considered to be a response to the increased work load associated with anemia per se [1]. The present study suggests that other factors contribute to the cardiac hypertrophy that accompanies iron and copper deficiency. In the rat, the increase in heart size is largely attributable to a disproportionate augmentation of mitochondrial mass. A rough estimate of the mitochondrial contribution to the increased heart weight ratio can be made as follows: The myocardium is made up almost entirely of mitochondria and myofibrils (fig. 1). For the purpose of an approximation, the contributions of blood vessels, nuclei, glycogen, and small structures are discounted and all components of the myocardium are assumed to have a density of 1.0. The weight-restricted, completediet group IB and iron-depleted group II B are similar in body weight. Of the average $0.28 \mathrm{~g}$ of heart muscle/

plete $\operatorname{diet}(\mathrm{I} A)$. In the specimen from the iron-deficient animal (IIB), the two peaks are normal relative to one another. The small differences in absolute height of the $c+c_{1}$ peaks in the three groups presumably reflect variations in yield of the mitochondrial fraction and are not significant. 
$100 \mathrm{~g}$ body weight in group IB (table I) about $0.12 \mathrm{~g}$ is mitochondrial (calculated from the mitochondrial/ myofibrillar ratio in table II). In group IIB, of the $0.65 \mathrm{~g}$ of heart muscle $/ 100 \mathrm{~g}$ body weight about $0.41 \mathrm{~g}$ is mitochondrial. The difference in mitochondrial weight is therefore roughly 0.29 , or about $75 \%$ of the $0.37 \mathrm{~g}$ difference in mean heart weight between the two groups.

The present findings underline the thesis that iron deficiency is a systemic disease in which anemia is simply the most easily recognizable manifestation. Ultrastructural studies of bone marrow samples from iron-deficient infants have shown unusually enlarged mitochondria in normoblasts and reticulocytes [8], similar to those observed in iron-deficient animals; sampling of other tissues in man rarely seems justifiable. Cardiac hypertrophy in iron-deficient patients may persist long after reversal of anemia [11]. Mitochondria constitute a smaller proportion of the myocardium in man than in the rat, however, and their contribution to cardiac enlargement is a matter for conjecture.

The morphological changes in rat mitochondria are not similar to those observed in work hypertrophy, nor are they attributable to inanition (group IA). Experimental conditions designed to increase cardiac work load have not resulted in a sustained increase in the estimated mass of the mitochondria in relation to myofibrils. In the dog with cardiac hypertrophy following chronic aortic stenosis, WoLlenberger and Schulze [27] illustrated by electron microscopy a somewhat greater increase in the myofibrillar rather than in the mitochondrial area. Two dogs that developed heart failure had some unusually elongated mitochondria but no overall increase in relative mitochondrial mass.

Meerson et al. [20] subsequently showed that cardiac ultrastructure followed a definite sequence of changes in the rabbit after the creation of aortic stenosis. A period of 'compensatory hyperfunction' during the first week was characterized by an augmentation in mitochondrial mass marked by destructive changes, including a decrease in the density of cristae. During the period of 'stable hyperfunction', between 1.5-8 months after the operation, individual mitochondria were enlarged but the relative area of mitochondria was less than in control animals while the area occupied by myofibrils was increased. A later or more severe 'stage of exhaustion' was characterized by cell atrophy and fibrosis. This study emphasizes the extent to which the ultrastructural appearance of the heart varies with the duration and magnitude of the increased work load.

The destructive changes and decreased density of cristae in mitochondria were features also noted by Wollenberger and Schulze [27] and in an earlier study of Molbert and Irjma [21]. More recently,
MaCAllister and Brown [19] studied rats with hypertensive cardiomegaly of about 6 weeks' duration. Electron micrographs showed no difference between control and hypertrophic specimens in the number of mitochondria or in the percentage of each field that they occupy. All these studies suggest that compensated work hypertrophy involves a relatively balanced increase in the energy-producing mitochondrial compartment that is equalled or exceeded by the expansion of the energy-consuming myofibrillar compartment.

The biochemical and functional significance of the morphological alterations in the myocardium remains obscure. There is no evident association between the degree of depression of one or more mitochondrial cytochromes and the extent of morphological change. Although the copper-deficient animals have a disproportionate depression in cytochrome $a+a_{3}$ this was not the case in the iron-deficient animals where the mitochondrial cytochromes were essentially normal in relative proportions and absolute concentration while the morphological changes were most striking. Copper- and iron-deficiency each result in distinctive biochemical changes, but copper also plays a role in iron transport $[14,17]$. This may account for manifestations of copper deficiency such as anemia. Some contribution of abnormal iron transport in the production of the cardiac abnormalities in the copper-depleted animals cannot be excluded.

In situ alterations in mitochondrial configuration with changes in metabolic state are described in intestinal mucosa [16]. In response to an increased energy demand, a high proportion of jejunal mitochondria assume a condensed configuration that appears associated with a high rate of coupled oxidative phosphorylation. The morphological changes do not resemble those in the present study, but an alteration in metabolic state cannot be excluded as a mechanism for the production of in situ mitochondrial enlargement in the myocardium. There is no evidence that a simple fluid shift to the heart is responsible for mitochondrial swclling since previous studies have shown the water content and protein of heart muscle to be normal in iron- and copper-deficient [7] animals.

The relative rates of respiration and phosphorylation of mitochondrial fractions from heart muscle and liver were measured to determine whether the morphological abnormalities observed were accompanied by an alteration in this variable of mitochondrial function. The ADP/O ratios of mitochondria isolated from the deficient animals reflected no loss of efficiency. Particularly low mitochondrial yields (mitochondrial protein/g tissue) from heart muscle of iron-deficient rats raise the possibility that a disproportionate number of 'abnormal' mitochondria were not recovered. Even in the liver, however, where the recovery of mitochondria 
was similar in all groups, there was no alteration in the $\mathrm{ADP} / \mathrm{O}$ ratio of the mitochondria isolated from the deficient groups. WoHLRAB and JACOBS [26] also found little or no reduction in the $\mathrm{ADP} / \mathrm{O}$ ratios and respiratory control ratios with succinate or glutamatemalate as substrates in copper deficiency. Only the rate of respiration with ascorbate TMPD (tetramethylphenylene diamine, an artificial substrate used to estimate the activity of the cytochrome oxidase portion of the electron transport chain) was decreased in the cytochrome oxidase-deficient mitochondria. Interchain electron transport was postulated to be an important feature in the respiration of these mitochondria [26]. Neither our study nor the study of WoHLRAB and JACOBS provides evidence of an abnormality in mitochondrial function.

If there is an altered quantitative balance between the energy-producing mitochondrial elements and the contractile energy-consuming myofibrillar portion of the myocardium, an alteration in some other variable of cardiac function might be anticipated. The increase in the size of the mitochondrial compartment does not necessarily imply a more effective energy-producing apparatus. Gustafsson et al. have described an increase in mitochondrial area in the skeletal muscle of hypothyroid rats [15]; the oxidation of the citric acid cycle substrates was less effective per milligram of mitochondrial protein than in control animals. The correlation of the striking morphological abnormality with possible altered physiological function remains to be determined in copper and iron deficiency.

\section{References and Notes}

1. Blumgart, H.L. and Altschule, M.D.: Clinical significance of cardiac and respiratory adjustments in chronic anemia. Blood 3: 329 (1948).

2. Burch, H. B.; Hunter, F. E. Jr.; Combs, A. M. and Schutz, B. A. : Oxidative enzymes and phosphorylation in hepatic mitochondria from riboflavindeficient rats. J. biol. Chem. 235: 1540 (1960).

3. Butow, R. and Racker, E.: The role of non-heme iron in oxidative phosphorylation; in: A.SAN Pietro: Nonheme iron protein, p. 383 (Antioch Press, Yellow Springs, Ohio 1965).

4. Ghance, B. and Hagihara, B.: Direct spectroscopic measurements of interaction of components of the respiratory chain with adenosine triphosphate (ATP), adenosine diphosphate (ADP), phosphate, and uncoupling agents. Proc. 4th Int. Congr. Biochem., Moscow 1961, vol.5, p. 3 (Pergamon, London 1963).

5. Gifance, B. and Williams, G.R.: Respiratory enzymes in oxidative phosphorylation. I. Kinetics of oxygen utilization. J. biol.Chem. 217: 383 (1955).

6. Grosby, W.H.; Munn, J.I. and Furth, F.W.: Standardizing a method for clinical hemoglobinometry. US armed Forces med.J. 5: 693 (1965).

7. Dallman, P.R.: Cytochrome oxidase repair during treatment of copper deficiency: relation to mitochondrial turnover. J.clin. Invest. 46: 1819 (1967).

8. Dallman, P.R. and Goodman, J.R.: Mitochondrial enlargement in iron deficiency (Abstract). Society for Pediatric Research, Atlantic Gity, NJ, 1969, p. 47. (Blood, in press.)

9. Dallman, P.R. and Schwartz, H. G.: Distribution of cytochrome $\mathrm{c}$ and myoglobin in rats with dietary iron deficiency. Pediatrics 35: 677 (1965).

10. Dallman, P. R. and Sahwartz, H. G. : Myoglobin and cytochrome response during repair of iron deficiency in the rat. J.clin. Invest. 44: 1631 (1965).

11. Diamond, L.K. (unpublished data).

12. Donaldson, H.H.: The rat. Data and reference tables, p. 208 (Memoirs Wistar Inst. Anat. Biol., no.6, Philadelphia 1924).

13. Dunn, M.S.; Murphy, E.A. and Rockland, L. B.: Optimal growth of the rat. Physiol. Rev. 27. 72 (194'7).

14. Goodman, J.R. and Dallman, P.R.: Iron transport within erythrocytic cells: the role of copper. Blood 34: 747 (1969).

15. Gustafsson, R.; Tata, J.R.; Lindberg, O. and ERNSTER, L.: The relationship between the structure and activity of rat skeletal muscle mitochondria after thyroidectomy and thyroid hormone treatment. J. Cell Biol. 26: 555 (1965).

16. JASPER, D.K. and BRONK, J.R.: Studies on the physiological and structural characteristics of rat intestinal mucosa. Mitochondrial structure changes during amino acid absorption. J. Cell Biol. 38: 277 (1968).

17. Lee, G.R.; Naght, S.; Lukens, J.N. and GartWRIGHT, G.E.: Iron metabolism in copper-deficient swine. J.clin. Invest. 47: 2058 (1968).

18. Lemberg, M.R.: Cytochrome oxidase. Physiol. Rev. 49: 48 (1969).

19. MCCalluster, B.D. and Brown, A.L.: A quantitative study of myocardial mitochondria in experimental cardiac hypertrophy. Lab. Invest. 14: 692 (1965).

20. Meerson, F.Z.; Zaletayeva, T.A.; Lagưtchev, S.S. and Pshennikova, M. G.: Structure and mass of mitochondria in the process of compensatory hyperfunction and hypertrophy of the heart. Exp. Cell Res. 36: 568 (1964).

21. Molbert, E. and lijima, S.: Beitrag zur experimentellen Hypertrophie und Insuffizienz des Herz- 
muskels in electronenmikroskopischem Bild. Naturwissenschaften 45: 322 (1958).

22. Porter, H.: Solubilization of the copper and protein from mitochondria of newborn liver by reduction with mercaptoethanol. Biochim. biophys.Acta 154: 236 (1968).

23. Suzukr, K.: Giant hepatic mitochondria: production in mice fed with cuprizone. Science 163: 81 (1969).

24. TAndler, B.; Erlandson, R. A.; Smith, A. L. and WYNDER, E. L.: Riboflavin and mouse hepatic cell structure and function. II. Division of mitochondria during recovery from simple deficiency. J. Cell Biol. 41: 477 (1969).

25. Tyler, D.D. and Gonze, J.: Preparation of heart mitochondria from laboratory animals; in: R.W. Estabrook, M.E.Pullman: Methods in enzymology, vol.X., p. 75 (Academic, New York 1967).

26. Wohlrab, H. and Jacobs, E. E.: Copper-deficient mitochondria, electron transport and oxidative phosphorylation. Biochem. biophys. Res. Commun. 28: 998 (1967).

27. Wollenberger, A. and Schulze, W.: Mitochondrial alterations in the myocardium of dogs with aortic stenosis. J. Biophys. biochem. Cytol. 10: 285 (1961).

28. The authors acknowledge the skillful technical assistance of Miss Lena Danielsson and Mrs. Vrbeke Craig.

29. Imferon, Lakeside Laboratories Inc., Milwaukee, Wisconsin.

30. Dr. Peter R. Dallman was the recipient of Public Health Service Research Career Development Award no. HE 31766.

31. Requests for reprints should be addressed to: JoSEPH R. Goodman, Veterans Administration Hospital, San Francisco, California 94121 (USA).

32. Accepted for publication November 6, 1969. 